引用格式: 张彪, 王爽, 李庆旭, 等. 基于防风固沙服务空间流动的区域关联度: 以京津风沙源治理工程区为例 [J]. 资源科学, 2020, 42(5): 969-979. [Zhang B, Wang S, Li Q X, et al. Regional correlation degree derived from the sand-fixing service spatial flow: A case study of the Beijing-Tianjin sandstorm control engineering area[J]. Resources Science, 2020, 42(5): 969-979.] DOI: 10.18402/resci.2020.05.14

\title{
基于防风固沙服务空间流动的区域关联度 一京津风沙源治理工程区为例
}

\author{
张 彪 ${ }^{1,2}$, 王 爽 ${ }^{1,2}$, 李庆旭 ${ }^{1,2}$, 谢高地 ${ }^{1,2}$ \\ (1. 中国科学院地理科学与资源研究所, 北京 100101 ; \\ 2. 中国科学院大学资源与环境学院, 北京 100049)
}

\begin{abstract}
摘 要: 定量评价生态系统服务供给区与受益区的生态联系程度是制定区域生态补偿政策的重要依据。该文 基于修正风蛨方程 (RWEQ), 并结合京津风沙源治理工程区(以下简称“工程区”)的风向、风速与土壤尘粒组成,构 建了由防风固沙供给度与影响度组成的区域关联度模型,分析了 2015 年工程区与北京市之间的防风固沙服务关联 度。结果表明:工程区内不同县域与北京市的防风固沙关联度介于 $0 \%$ 13.43\%。其中赤城县最高, 苏尼特左旗、宣 化区、怀安县、下花园区和苏尼特右旗等地区较高, 翁牛特旗、承德县、宁城县、蓟县与阳原县等地区与北京市的防 风固沙关联度不明显。整体来看，区域防风固沙关联度呈现出西高东低、多区镶嵌的空间格局，这主要与工程区主 导风向和防风固沙能力的差异有关。此外, 工程区内不同县域的防风固沙关联度与其社会经济发展水平有一定程 度的负相关。因此,作为防风固沙服务的受益区, 北京市应优先考虑工程区西部高度关联地域的生态补偿,提高其 社会经济发展水平,进而保障防风固沙服务的持续供给。
\end{abstract}

关键词: 防风固沙服务; 空间流动; 生态联系; 区域关联度; 京津风沙源治理工程区

DOI :10.18402/resci.2020.05.14

\section{1 引言}

生态系统服务流动是实现生态服务供给与需 求耦合的桥梁, 也是生态系统服务研究的热点与 前沿 ${ }^{[1]}$ 。生态系统服务流动是指供给区所提供的生 态系统服务依靠某种载体或介质, 在自然或人为因 素的驱动下传递到受益区的过程 ${ }^{[2-4]}$ 。生态服务流 动现象的存在使区域内形成具有生态联系的某些 地域, 比如流域、风域或资源域等 ${ }^{[5]}$ 。生态联系最早 由 Robinson ${ }^{[6]}$ 提出, 并用于定量解释不同组织间的 行为关联程度。在中国生态环境问题愈加呈现区 域化特征的背景下, 高吉喜等 ${ }^{[7]}$ 将区域生态联系定 义为 “生态区域内不同生态功能体通过一种或几种 生态介质所产生的联系”。

不过, 如何准确衡量区域生态联系是生态学研
究的难点。早在 2005 年, Maass 等 ${ }^{[8]}$ 通过评估墨西 哥太平洋西岸热带干旱森林 9 项生态系统服务, 勾 画了从供给区向受益区输送的示意图; Turner 等 ${ }^{[9]}$ 借 助空间流动模型, 建立了生态服务供给区与受益区 的空间关系; 而 Palomo 等 ${ }^{[10]}$ 则利用参与式调查法, 分析了西班牙西南部沿海国家公园生态服务的供 给区与受益区。此外, Xu等 ${ }^{[11]}$ 基于 HYSPILT 模型, 模拟了宁县、盐池县防风固沙服务空间流动的受益 区与影响因素; 杨丽雯等 ${ }^{[12]}$ 基于 SPANs 模型,评估了 引黄人晋南干线固碳服务供需平衡, 绘制了服务流 传输路径图并量化服务流; 朱文博等 ${ }^{[13]}$ 以食物供给、 淡水供给和固碳服务为例,运用生态系统服务足迹 算法和多区域间投人产出模型,核算分析了中国省 区典型生态系统服务足迹和省域间动态流动及其

收稿日期: 2018-12-10,修订日期: 2019-07-04

基金项目: 国家重点研发计划项目(2016YFC0503403)。

作者简介: 张彪, 男, 山东郓城人, 副研究员, 博士, 主要研究方向为生态系统服务与生态补偿。E-mail: zhangbiao@igsnrr.ac.cn 
影响因素; 而Shi 等 ${ }^{[14]}$ 评估识别了上海市食物供给、 固碳释氧、休闲游憩和生境维护的生态服务供给区 与需求区,并模拟了生态服务流动方向。不过,以 往相关研究重视刻画生态系统服务的空间流动路 径, 缺乏生态服务流向与流量的综合考量, 而定量 评价区域生态联系程度的研究更少。

定量评估区域生态联系, 对于揭示重大生态工 程的区域贡献以及识别优先补偿对象尤其重要。 京津风沙源治理工程是为遏制北京及周边地区土 地沙化趋势、改善京津地区大气环境质量而实施的 一项重大生态工程。近年来该工程区域植被恢复 取得明显成效 ${ }^{[15,16]}, 2000-2015$ 年植被覆盖度以 $0.4 \% /$ 年的速率波动增加 ${ }^{[17]}$ 。区域植被恢复有效提 升了其防风固沙功能 ${ }^{[1,19]}$, 改善了京津冀地区生态 环境 ${ }^{[20]}$, 理应给予防风固沙供给区更多的生态补 偿 ${ }^{[2]}$ 。但是, 目前中国生态补偿中受偿主体的识别 技术不足, 多依赖定性描述的生态补偿优先度 ${ }^{[22]}$ 因此,在有限的生态补偿预算额度下, 定量测算区 域生态联系有助于识别需优先补偿的地区以及分 配补偿资金。

综上所述,定量评价区域生态联系需要综合考 量生态系统服务的流向与流量, 同时区域生态补偿 政策制定也需要识别确定区域的生态联系程度 ${ }^{[23]}$ 。 为此, 本文将区域关联度界定为区域内不同地区间 的生态联系程度, 采用生态系统服务供给区与受益 区之间生态服务流动的有效数量及影响程度来表 示, 并以京津风沙源治理工程区为例, 基于修正风 蚀方程 (RWEQ) 与工程区气象及土壤特征, 构建防 风固沙服务的区域关联度模型, 以定量测算工程区 与北京市在防风固沙服务上的生态联系程度, 从而 建立区域生态联系的定量评价模型, 并为区域生态 补偿政策制定提供新工具。

\section{2 研究区概况}

京津风沙源治理工程区 (以下简称“工程区”) 位于 $109^{\circ} 30^{\prime} \mathrm{E}-114^{\circ} 20^{\prime} \mathrm{E}, 38^{\circ} 50^{\prime} \mathrm{N}-46^{\circ} 40^{\prime} \mathrm{N}$, 西起 内蒙古达尔军茂明安联合旗, 东至河北省平泉县, 南起山西省代县, 北至内蒙古东乌珠穆沁旗。一期 工程区国土面积为 45.8 万 $\mathrm{km}^{2}$, 涵盖北京、天津、锡 林郭勒、乌兰察布、赤峰、承德、张家口等 11 地市的 75 个县(市、区、旗)。
工程区地貌主要由平原、山地和高原组成。其 中, 东部浑善达克沙地是锡林郭勒高原的重要组成 部分, 沙化土地广布; 西部乌兰察布高原由阴山北 麓的丘陵、地势平缓的凹陷地带及横贯东西的石质 丘陵隆起带组成, 境内多季节性河流; 燕山山地和 太行山地形起伏较大, 地形雨较多, 易造成水土流 失。内蒙古高原地带性土壤以温带、暖温带条件下 形成的黑钙土、栗钙土、棕钙土为主。其中栗钙土 占绝对优势, 燕山山地以石灰土、石质土为主 ${ }^{[24]}$ 。

工程区气候跨 2 个气候带, 包含暖温带半湿润 大区、温带半湿润大区、温带半干旱大区、温带干旱 大区、温带极干早大区 5 个气候大区。区内多年平 均气温为 $7.5^{\circ} \mathrm{C}$, 年平均降水量和蒸发量分别为 $459.5 \mathrm{~mm}$ 和 $2110.0 \mathrm{~mm}$, 年大风日数高达 36.2 天。 内蒙古高原干旱、半干旱气候特征明显, 且多大风 和沙尘暴天气,是京津地区的主要风沙来源。

风沙源治理一期工程 (2001-2010 年)已于 2012 年 (展期两年)结束, 同年, 二期工程 (20132022 年)决定实施。一期工程实施期间,工程区内 的耕地、草地、湿地以及荒漠沙地面积均有所减小, 而林地与城乡建设用地面积均明显增加。同时,农 牧业产值大幅提高, 但种植业占第一产业比重明显 下降,第一产业劳动力向二、三产业转移趋势明 显。截至 2015 年, 工程区内有草地面积 2806 万 $\mathrm{hm}^{2}$, 占到工程区的 $62 \%$, 其次为耕地和林地, 面积 分别有 760 万 $\mathrm{hm}^{2}$ 和 540 万 $\mathrm{hm}^{2}$, 同时分布有一定面 积的荒漠沙地 $(6 \%)$, 而湿地和城乡建设用地面积较 小(图 1)。

\section{3 研究方法与数据}

\section{1 修正风蚀方程 (RWEQ)}

防风固沙服务是指植被生态系统抑制或降低 土壤风蚀的作用, 通过有无植被覆盖时的土壤风蚀 量来计算 ${ }^{[18]}$, 修正风蚀方程 (RWEQ) 目前已广泛应 用于中国土壤风蚀状况的评估 ${ }^{[25-27]}$ 。为此,本文基 于 RWEQ 模型评估京津风沙源治理工程区栅格单 元 $(100 \mathrm{~m} \times 100 \mathrm{~m})$ 防风固沙服务的供给状况。

首先, 采用无植被覆盖时的土壤风蚀量表示潜 在风蚀量 $\left(S L_{\mathrm{p}}\right)$, 计算公式为 $(1)-(3)$ :

$$
S L_{\mathrm{p}}=\frac{2 Z}{s p^{2}} \times Q_{\mathrm{p} \max } \times e^{-(z / s p)^{2}}
$$




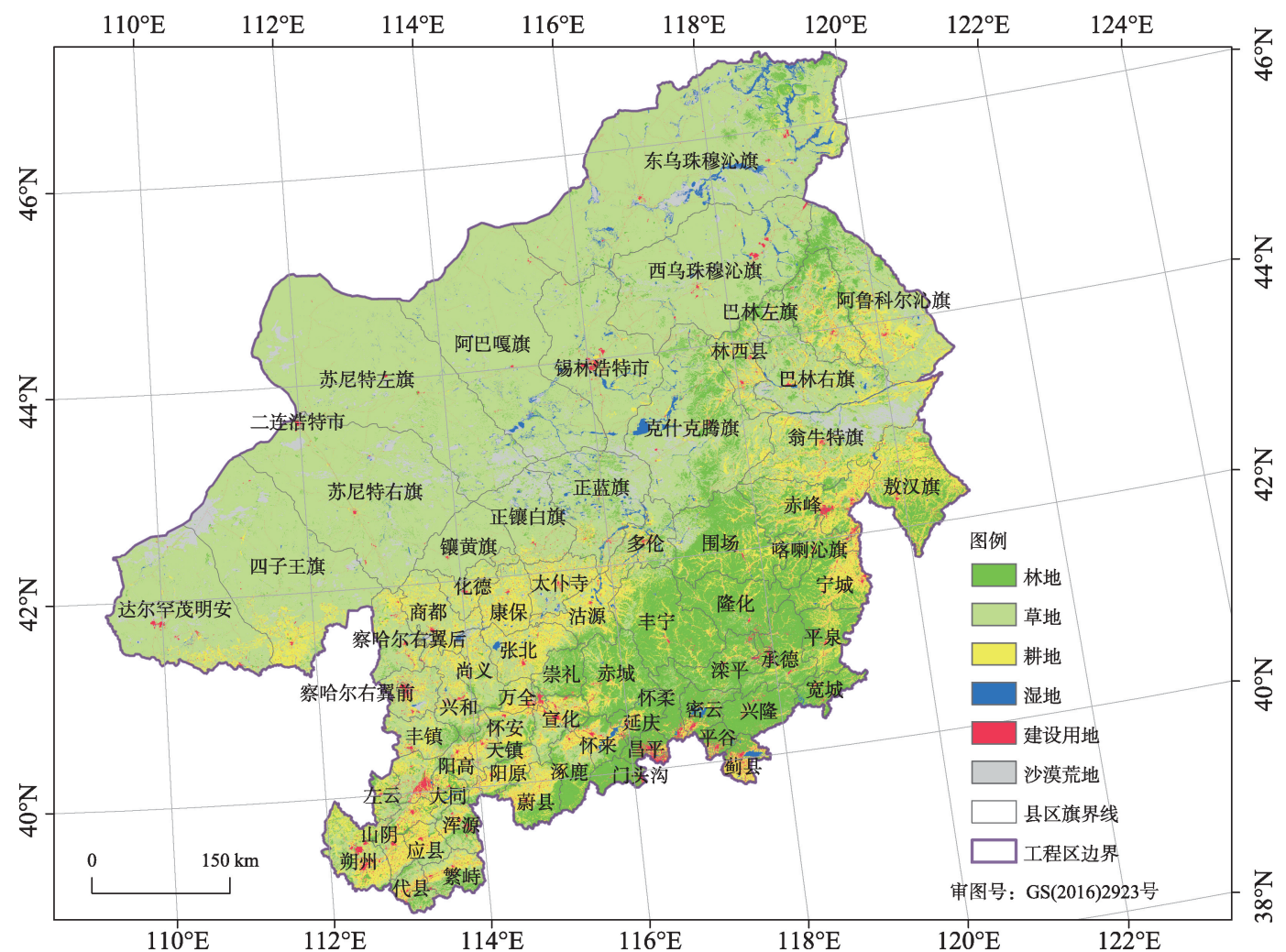

图 12015 年京津风沙源治理工程区土地利用状况

Figure 1 Land use of the Beijing-Tianjin sandstorm control engineering area, 2015

$$
\begin{gathered}
Q_{\mathrm{p} \max }=109.8 \times\left(W F \times E F \times S C F \times K^{\prime}\right) \\
s p=150.71 \times\left(W F \times E F \times S C F \times K^{\prime}\right)^{-0.3711}
\end{gathered}
$$

式中: $S L_{\mathrm{p}}$ 为潜在风蚀量 $\left(\mathrm{g} / \mathrm{m}^{2}\right), Q_{\mathrm{p} \text { max }}$ 为潜在风力的 最大输沙能力 $(\mathrm{kg} / \mathrm{m}), s p$ 为潜在关键地块长度 $(\mathrm{m})$, $z$ 表示下风向距离 $($ 取 $50 \mathrm{~m}), W F$ 为气候因子 $(\mathrm{kg} / \mathrm{m})$, $E F$ 和 $S C F$ 分别为土壤可蚀性因子和土壤结皮因子, $K^{\prime}$ 为土壤䊁度因子, 上述参数因子计算方法参考江 凌等 ${ }^{[17]}$ 。

其次, 采用植被覆盖状况下的土壤风蚀量代表 实际风蚀量 $\left(S L_{\mathrm{r}}\right)$, 计算公式为 $(4)-(6)$ :

$$
\begin{gathered}
S L_{\mathrm{r}}=\frac{2 Z}{s r^{2}} \times Q_{\mathrm{r} \max } \times e^{-(z / s r)^{2}} \\
Q_{\mathrm{r} \max }=109.8 \times\left(W F \times E F \times S C F \times K^{\prime} \times C\right) \\
s r=150.71 \times\left(W F \times E F \times S C F \times K^{\prime} \times C\right)^{-0.3711}
\end{gathered}
$$

式中: $S L_{\mathrm{r}}$ 为实际风蚀量 $\left(\mathrm{kg} / \mathrm{m}^{2}\right), Q_{\mathrm{r} \text { max }}$ 为实际风力的 最大输沙能力 $(\mathrm{kg} / \mathrm{m}), s r$ 为实际关键地块长度 $(\mathrm{m})$, $C$ 为植被因子。

再次, 年防风固沙量 $(S R Q)$ 即为潜在土壤风蚀 量 $\left(S L_{\mathrm{p}}\right)$ 与实际土壤风蚀量 $\left(S L_{\mathrm{r}}\right)$ 的差值式 $(7)$; 最
后, 地域内所有栅格单元固沙量加和得到行政区尺 度的年防风固沙量式 $(8)$ :

$$
\begin{gathered}
S R Q=10 \times\left(S L_{\mathrm{P}}-S L_{\mathrm{r}}\right) \times A \\
S L_{\text {固 }}=\sum_{i=0}^{n} S R Q_{i}
\end{gathered}
$$

式中 : $S R Q$ 与 $S L$ 固分别为栅格单元与县域尺度的年 防风固沙量 $(\mathrm{t} / \mathrm{a}), A$ 为栅格单元面积 $\left(\mathrm{hm}^{2}\right), i$ 为栅格 单元, $n$ 为栅格数。

\section{2 防风固沙服务流动}

为简化研究, 本文将京津风沙源治理工程区作 为防风固沙服务的供给区,工程区内不同县域的防

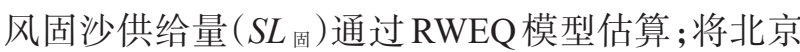
市作为受益区, 由供给区流动至受益区的有效防风 固沙量 $(S L$ 特 $)$ 主要与供给区的风向、风速与沙尘可 输送距离有关。为此, 根据工程区内各县域 2015 年 不同风向的频率,计算其在北京市 (中心)风向上的 防风固沙量 $(W S L$ 输)，计算公式为:

$$
W S L_{\text {输 }}=\delta \times S L_{\text {固 }}
$$

式中: $W S L$ 输为北京市 (中心) 风向上的防风固沙量 
(t), $\delta$ 为各县域在北京市 (中心)风向上的风频 $(\%)$ 。

区域沙尘传输距离与风速和沙尘粒径有关。 工程区影响到京津地区的沙尘主要是粒径小于 20 $\mu \mathrm{m}$ 的土壤尘粒 ${ }^{[28]}$ 。依据工程区内不同县域在北京 市 (中心) 风向上 2015 年最大风速月平均值, 可确定

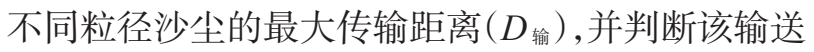
距离与各县域在北京市 (中心) 风向上空间距离 $(D)$ 之间的大小关系: 即当沙尘传输距离 ( $D$ 输) 小于空间 距离 $(D)$ 时, 该防风固沙服务无法流动到北京市 (中 心), 有效防风固沙量为 0 ; 反之则认为有效防风固 沙量 $\geqslant 0$, 通过各县域不同土壤粒径含量与北京市 (中心)风向上的防风固沙量计算,计算公式如下:

$$
S L_{\text {输 }}=\left\{\begin{array}{l}
0, D_{\text {输 } k}<D \\
\sum_{k=1}^{20} W S L_{\text {输 }} \times S P_{k}, D_{\text {输 } k} \geqslant D
\end{array}\right.
$$

式中: $S P_{k}$ 为各县域土壤表层 $k$ 粒径的尘粒含量 $(\%)$,

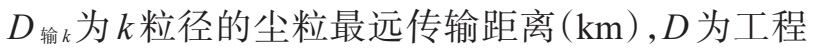
区不同县域 (中心)在北京市 (中心) 风向上的空间 距离 $(\mathrm{km}), k$ 为不同粒径等级。

\section{3 区域关联度模型}

区域关联度是定量反映生态系统服务供给区 与受益区生态联系程度的指标。本文以防风固沙 服务为例, 将区域关联度 $(R E C)$ 界定为防风固沙服 务由供给区有效流动至受益区的程度, 由两项指标 构成: (1)防风固沙服务供给度 (WSP), 即供给区流动 至受益区的防风固沙量占供给区防风固沙总量的 比值; (2)防风固沙服务影响度 (WSC), 即供给区流 动至受益区的防风固沙量占受益区接收防风固沙 服务量的比例。因此,工程区内不同县域与北京市 的防风固沙关联度可通过防风固沙服务的供给度 与影响度加权得到, 计算公式如下:

$$
\begin{gathered}
W S P=\frac{S L_{\text {输 }}}{S L_{\text {固 }}} \times 100 \\
W S C=\frac{S L_{\text {输 }}}{\sum_{j=1}^{75} S L_{\text {输 }}} \times 100 \\
R E C=\alpha \times W S P+\beta \times W S C
\end{gathered}
$$

式中: $R E C$ 为防风固沙服务关联度 $(\%), \alpha$ 和 $\beta$ 分别 为防风固沙供给度与影响度的权重(本次均取 0.5 ), $j$ 为工程区 75 个县域单元。

\section{4 数据来源与处理}

本文需要获取风速、土壤、植被等多项参数因 子及数据源。其中, 京津风沙源治理工程区内分布 有 26 个气象站 ${ }^{[29]}$, 气象因子参数采用 2015 年逐月观 测数据插值所得, 数据值来源于中国气象科学数据 共享服务网 (http://cdc.cma.gov.cn/), 雪盖因子利用 中国西部环境与生态科学数据中心 (http://westdc. westgis.ac.cn) 的雪深长时间序列数据集计算。土壤 数据来源于中国西部环境与生态科学数据中心 (http://westdc.westgis.ac.cn) 的 1:100万土壤图, 以 及所附的土壤属性表和空间数据。NDVI数据来自 美国地球资源观测系统数据中心的 MOD13Q1 产 品, 并采用最大值合成法获得 2015 年 NDVI数据。 以上因子均重采样为 $100 \mathrm{~m} \times 100 \mathrm{~m}$ 栅格单元, 并参 与模型计算。此外,工程区土壤粒径组成与不同风 速下被搬运的距离均参考自高尚玉等 ${ }^{[28]}$ 的研究结 果, 工程区内不同县(市、区、旗)社会经济数据分别 来自河北省、山西省及内蒙古自治区2016年统计年 鉴及社会经济发展公报。

\section{4 结果与分析}

\section{1 防风固沙服务流动量}

基于 RWEQ 评估结果, 2015 年京津风沙源治理 工程区可提供防风固沙量 31.2 亿 $\mathrm{t}$ 。其中苏尼特左 旗的防风固沙量最高 (3.0亿t), 占到工程区防风固 沙量的 $9.66 \%$; 其次为东乌珠穆沁旗、阿巴嘎旗、苏 尼特右旗和四子王旗, 分别提供了 2.44 亿 $\mathrm{t} 、 2.19$ 亿 t、1.98亿 $\mathrm{t}$ 和 1.66 亿 $\mathrm{t}$ 的防风固沙量; 克什克腾旗、西 乌珠穆沁旗、正蓝旗和达尔罕茂明安联合旗的防风 固沙量均占到工程区的 $4 \% \sim 5 \%$ 。因此,上述 9 个地 区年防风固沙量合计为 16.8 亿t, 占到防风固沙总量 的 $53.75 \%$, 是工程区防风固沙服务的主要供给者。

根据工程区内气象观测数据, 2015 年工程区主 导风向为西北风,大风日的平均风速为 $7 \mathrm{~m} / \mathrm{s}$ 。其中 西北风 (NW) 频率最高 $(33 \%)$, 其次为西南风 (SW), 其风频达到 $13 \%$, 东北风 (NE) 和西风(W)频 率均接近 $10 \%$, 而东风(E) 的频率最低 $(3 \%)$ 。此外, 不同风向上最大月均风速有一定差异, 但差别不 大, 其中西风向 $(\mathrm{W})$ 最高 $(7.42 \mathrm{~m} / \mathrm{s})$, 其次为西北风 $(\mathrm{NW})$ 、西南风 $(\mathrm{SW})$ 和南风 $(\mathrm{S})$ 风向, 月最大风速分 
别为 $7.08 \mathrm{~m} / \mathrm{s} 、 6.81 \mathrm{~m} / \mathrm{s}$ 和 $6.24 \mathrm{~m} / \mathrm{s}$, 而东风( $E$ ) 的月 最大风速最小 $(4.87 \mathrm{~m} / \mathrm{s})$ (图 2$)$ 。

基于 ArcGIS10.2 的空间距离分析发现, 2015 年 工程区内 13.6 亿 $\mathrm{t}$ 的防风固沙服务可有效流动至北 京市。其中苏尼特左旗最高 $(0.17$ 亿 $t)$, 占到防风固 沙服务有效流动量的 $12.38 \%$; 其次为苏尼特右旗、 阿巴嘎旗和四子王旗, 分别有 0.13 亿 $\mathrm{t} 、 0.12$ 亿 $\mathrm{t} 、 0.10$ 亿 $\mathrm{t}$ 的防风固沙服务可流动至北京市; 达尔罕茂明 安联合旗、正蓝旗、东乌珠穆沈旗和赤城县可提供 给北京市的有效防风固沙量均在 0.07 亿 0.08 亿 $\mathrm{t}$ 。 因此, 上述 8 个地区共为北京市提供了有效防风固 沙量 0.80 亿 $\mathrm{t}$, 累计占比达到 $58.76 \%$, 是北京市防风 固沙服务的有效供给者。

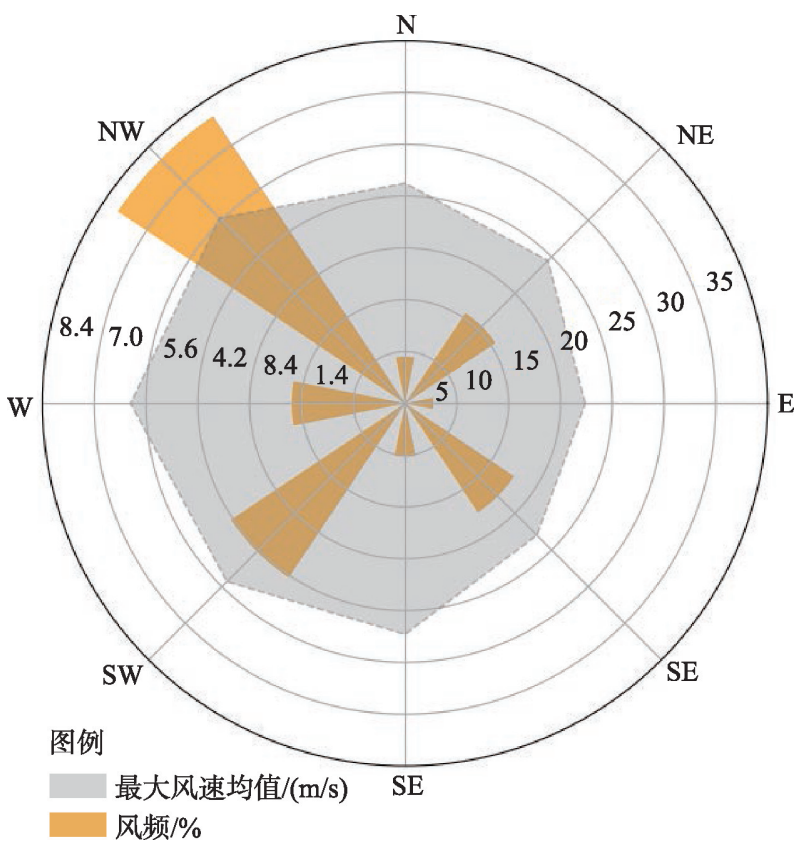

图 22015 年工程区风频与月均最大风速

Figure 2 Wind frequency and monthly highest wind speed of the Beijing-Tianjin sandstorm control engineering area, 2015

\section{2 区域关联度差异分析}

评估结果表明,工程区内各县域与北京市的防 风固沙关联度分布在 $0 \%$ 13.43\%之间 (表 1 )。其中 承德县、宽城县与㴒平县等 16 个地区的关联度低于 $0.1 \%$, 原因在于其防风固沙服务的供给度与影响度 均极低; 克什克腾旗、林西县、多伦县和敖汉旗的关 联度介于 $0.1 \% \sim 1 \%$, 其防风固沙供给度均有所增 大, 但影响度仍较低; 东乌珠穆沈旗、西乌珠穆沈旗 与巴林左旗等 23 个地区的关联度分布在 $1 \%$ ～4\% , 防风固沙服务的供给度与影响度均明显增大; 正蓝 旗、正镶白旗和达尔罕茂明安联合旗等 18 个地区的 关联度在 $4 \% \sim 6 \%$, 主要受益于防风固沙供给度较 高; 而苏尼特右旗、阿巴嘎旗与四子王旗等 13 个地 区的关联度高于 $6 \%$, 防风固沙服务的供给度与影 响度均表现出高值, 其中赤城县与北京市的防风固 沙关联度最高。

从空间分布来看, 高度关联区主要分布在苏尼 特左旗、苏尼特右旗、阿巴嘎旗、四子王旗, 以及张 家口市的万全县、崇礼县、赤城县、怀安县、宣化区 和山西丰镇县等; 位于工程区中部的正蓝旗、正镶 白旗、镶黄旗、达尔罕茂明安联合旗和化德县、康保 县、怀来县、涿鹿县等与北京市的防风固沙服务关 联度较高; 位于工程区东北部的东乌珠穆沈旗、西 乌珠穆沈旗、巴林左旗, 以及承德市的围场县、隆化 县、丰宁县和山西省部分地区与北京市防风固沙服 务的关联度处于一般水平;受主导风向与植被面积 的影响, 关联度较低区域分布在工程区中北部的克 什克腾旗、林西县、多伦县和敖汉旗;位于工程区东 南部的喀喇沁旗、宁城县、平泉县、兴隆县, 以及山 西天镇县、阳高县和阳原县等均表现出防风固沙服 务的低关联度 (图 3)。整体来看, 工程区与北京市

表 1 工程区与北京市的防风固沙服务关联度分级

Table 1 Grades of regional correlation of annual sand-fixing services between the sandstorm control engineering area and Beijing

\begin{tabular}{|c|c|c|c|c|c|}
\hline 分级 & 关联度 $/ \%$ & 供给度 $/ \%$ & 影响度/\% & 县域/个 & 典型地区 \\
\hline 低度关联 & $<0.1$ & $<0.1$ & $<0.1$ & 16 & 承德县、宽城县、㴒平县、兴隆县、平泉县 \\
\hline 较低关联 & {$[0.1,1]$} & {$[0.1,1.2]$} & {$[0.1,0.6]$} & 4 & 克什克腾旗、林西县、多伦县和敖汉旗 \\
\hline 中度关联 & $(1,4]$ & $(1.2,6.0]$ & $(0.6,4.8]$ & 23 & 东乌珠穆沈旗、西乌珠穆沁旗、巴林左旗、围场县、隆化县、丰宁县 \\
\hline 较高关联 & $(4,6]$ & $(6.0,9.6]$ & $(4.8,5.7]$ & 18 & $\begin{array}{l}\text { 正蓝旗、正镶白旗、镶黄旗、达尔罕茂明安联合旗和化德县、康保县、 } \\
\text { 怀来县、溷鹿县 }\end{array}$ \\
\hline 高度关联 & $(6,13.4]$ & $(9.6,22.0]$ & $(5.7,12.4]$ & 13 & $\begin{array}{l}\text { 苏尼特左旗、苏尼特右旗、阿巴嘎旗、四子王旗, 万全县、崇礼县、赤 } \\
\text { 城县、怀安县、宣化区和丰镇 }\end{array}$ \\
\hline
\end{tabular}




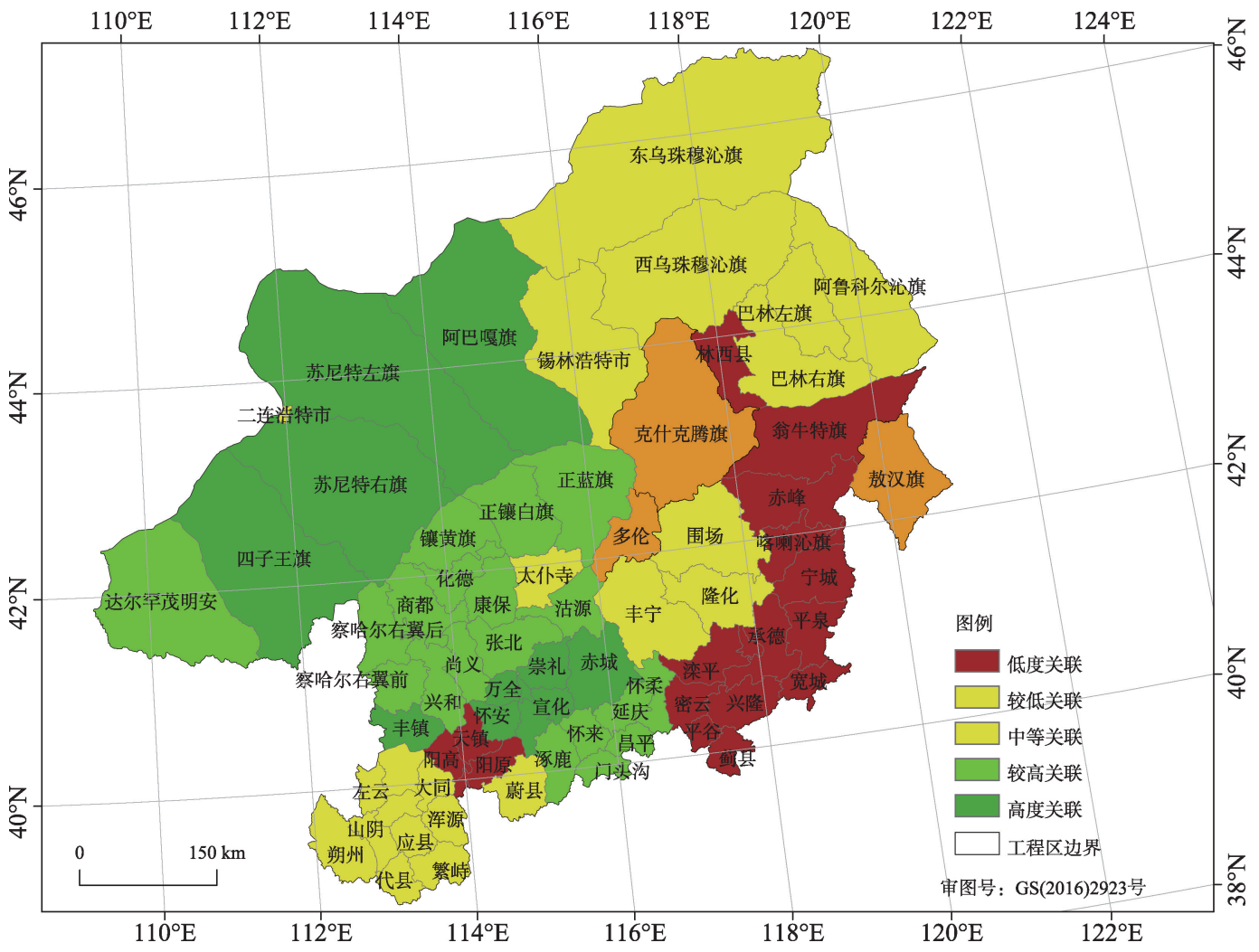

图 3 工程区与北京市的防风固沙服务关联度空间分布

Figure 3 Spatial distribution of correlation degree of sand-fixing services between the sandstorm control engineering area and Beijing

的防风固沙服务关联度呈现出西高东低、多区镶嵌 的空间格局, 这主要与工程区内主导风向和防风固 沙能力差异有关。

\section{3 关联区社会经济分析}

识别区域生态补偿的优先程度, 需要兼顾工程 区内不同县域社会经济发展差异。为此,对县域防 风固沙服务关联度与其社会经济指标开展相关分 析。基于工程区县域统计指标的可获得性,本文主 要选取医疗、教育和养老等社会公共服务水平代表 不同地区的社会进步程度 ${ }^{[30,31]}$, 选取人均 GDP 代表 经济实力水平 ${ }^{[32]}$, 并利用 SPSS 软件进行归一化处理 与分析。

首先将 2015 年工程区内县域人均医院床位数、 每万人中小学生数量以及人均养老院床位数指标 分别进行归一化处理,然后等权加和得到社会发展 指数。结果显示, 不同地区社会发展指数分布在 0.02 0.60 之间, 平均值为 0.2 , 表明工程区社会发展 水平整体较低。其中二连浩特、锡林浩特、镶黄旗 以及怀仁县的社会发展水平较高, 其他地区的社会
发展指数位于 0.4 以下 (图 4)。社会发展指数与区 域关联度的相关分析表明,各县域社会发展指数与 关联度呈一定程度的负相关关系 $(r=-0.198)$, 但不 显著 $(\operatorname{sig}=0.134>0.05)$ 。

依据 2015 年各地区 GDP 与常住人口数量, 计 算得到人均 GDP, 并进行归一化处理,代表工程区 内县域经济实力指数。从经济实力来看, 2015 年工 程区内县域人均 GDP 值位于 9598 335769 元的区 间,县域经济实力指数平均值为 0.13 , 表明工程区经 济实力水平整体较低。其中阳高县、蔚县、翁牛特 旗、宽城县、喀喇沈旗等经济实力指数较高, 均大于 0.4 ; 二连浩特市、镶黄旗、东乌珠穆沈旗和西乌珠穆 沁旗等经济实力指数较低,具体区间为 $0.03 \sim 0.11$ 。 随着防风固沙服务关联度的增加, 县域经济实力指 数呈明显降低趋势 (图 5), 不同地区经济实力指数 与区域关联度呈现出明显负相关关系 $(r=-0.60)$, 且 存在显著性 $(s i g=0.01)$ 。

上述分析表明,防风固沙服务关联度与工程区 社会经济发展状况有一定程度的负相关,即关联度 


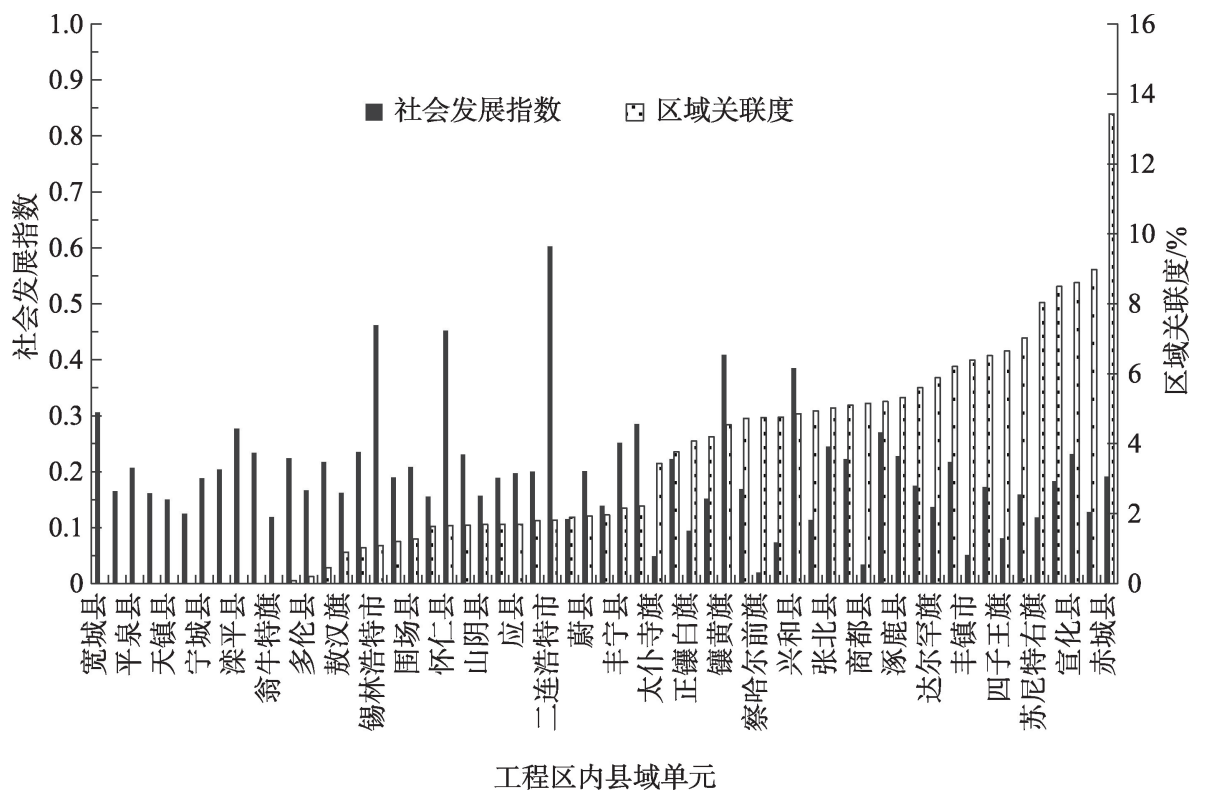

图 4 工程区不同地区社会发展指数与防风固沙关联度

Figure 4 Social development degree and correlation degree of sand-fixing services in the Beijing-Tianjin sandstorm control engineering area

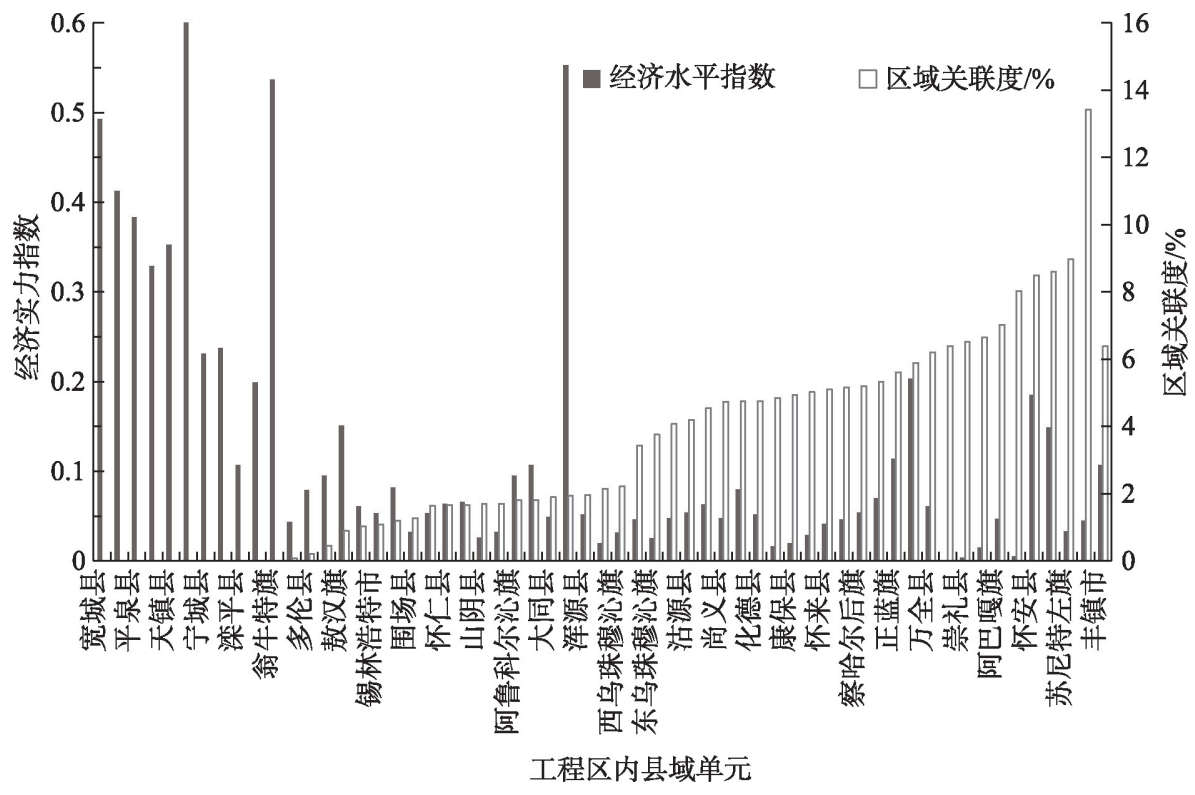

图 5 工程区不同地区经济实力指数与防风固沙关联度

Figure 5 Economic development degree and correlation degree of sand-fixing services in the Beijing-Tianjin sandstorm control engineering area

越大的地区社会经济水平越低, 原因可能在于区域 社会经济发展需要大量的资源环境投人, 而防风固 沙服务高供给区为保护植被生态而放弃了资源环 境的开发利用, 因而更加需要防风固沙受益区给与 适度的生态补偿。因此, 京津风沙源治理工程区的 防风固沙关联度可以作为生态补偿优先程度的判
断依据。

\section{5 结论与讨论}

\section{1 结论}

该研究以京津风沙源治理工程区为例, 基于 RWEQ 模型测算了工程区不同县域的防风固沙服 务供给状况, 并结合工程区风向、风速与土壤特征, 
模拟得到防风固沙服务流动至北京市 (中心) 的有 效数量, 在此基础上构建了定量表征生态联系程度 的关联度模型。结果发现：

(1)2015 年京津风沙源治理工程区可防风固沙 3.12 亿 $\mathrm{t}$, 其中北京市可有效受益的防风固沙服务为 1.36 亿 $\mathrm{t}$, 因而工程区内各县域与北京市的防风固沙 关联度分布在 $0 \%$ 13.43\% 之间，且该关联度呈现西 高东低、多区镶嵌的空间格局。

(2)工程区内赤城县与北京市的防风固沙关联 度最高, 万全县、崇礼县、怀安县以及苏尼特右旗、 苏尼特左旗、阿巴嘎旗、四子王旗等均表现出高关 联特征。

(3) 防风固沙关联度与工程区内县域社会经济 发展水平表现出一定程度的负相关关系。因此, 区 域生态关联度可作为生态补偿优先程度的判断依 据, 北京市应优先实施对高度关联地区的生态补 偿,进而保障防风固沙服务的持续供给。

\section{2 讨论}

生态系统服务存在一定程度的空间流动现象， 并在供给区与受益区之间产生生态联系。虽然已 有部分研究尝试刻画生态系统服务的空间流动路 径, 但尚未报道基于生态服务空间流动的生态联系 定量评价技术, 对区域生态补偿优先程度的识别需 求有一定制约。本文中建立的模型由防风固沙供 给度与影响度组成, 可定量反映生态系统服务供给 区与受益区之间生态服务流动的有效数量及影响 程度, 明显优于通过生态系统服务受益区面积占总 受益区面积比例 ${ }^{[3]}$ 或者供给区流动至受益区的生态 服务价值比例 ${ }^{[33]}$ 来衡量区域生态联系的做法。虽然 该文是基于 2015 年数据做出的区域生态联系定量 化研究, 随着时间的变化研究区的生态环境状况及 其防风固沙服务会发生一定程度的变化, 但是定量 评价区域防风固沙服务供给、流动以及联系程度的 思路与方法是不变的。此外, 该模型确定的区域关 联度与社会经济状况有一定程度的负相关性, 即高 生态服务供给区的社会经济发展程度一般较低, 这 与郜红娟等 ${ }^{[34}$ 、陈婧神等 ${ }^{[35}$ 关于区域社会经济发展 水平与生态系统服务负相关的论断相一致。

不过需要说明的是, RWEQ 模型是美国农业部
20 世纪 80 年代建立的经验模型,计算参数均来源于 美国大平原的统计值, 具有很强的地域性 ${ }^{[36]}$, 比如土 壤粒径分类系统、管理措施以及可蚀性边界等。受 RWEQ 模型限制, 风蚀基本单元不宜过大, 但本文 中气象、土壤以及遥感数据的空间分辨率均较低, 借鉴采用中国北方沙化地区的关键参数和处理方 法, 并对部分输人参数进行了插值处理, 可能导致 评估结果的误差与不确定性。此外, RWEQ 模型在 风蚀因子分类与相互影响方面存在不足, 风蚀影响 因子仅是特定区域的经验表达 ${ }^{[37]}$, 这些不确定因素 需要进一步完善与验证。同时,沙尘远距离传输包 括起沙、传输和沉降过程,涉及土壤表层沙粒、植被 类型和地表风应力等多种因素 ${ }^{[38-40]}$ 。该研究模拟防 风固沙服务流动时,未考虑不同变量要素之间的协 同耦合效应, 同时为便于传输距离与空间距离的判 断, 将县域空间中心视为供给区的起始点, 将北京 市中心作为受益点,但实际上工程区沙尘影响范围 远超京津地区。因此,未来研究应扩大研究区范围 以构建更大尺度上的防风固沙服务流动模型。还 有防风固沙服务仅是产生生态联系的众多生态服 务空间流动的一种 ${ }^{[41]}$, 该研究针对特定区域建立的 定量化区域生态联系的方法,有待纳人更多的生态 系统服务指标。尽管如此,本文提出了防风固沙服 务供给、流动与联系程度的定量化思路,并初步建 立了防风固沙服务的区域关联度模型, 可为区域生 态联系的定量化研究起到抛砖引玉的作用。

\section{参考文献(References):}

[1] 王嘉丽, 周伟奇. 生态系统服务流研究进展[J]. 生态学报, 2019, 39(12): 4213-4222. [Wang J L, Zhou W Q. Ecosystem service flows: Recent progress and future perspectives[J]. Acta Ecologica Sinica, 2019, 39(12): 4213-4222.]

[2] Bagstad K J, Johnson G W, Voigt B, et al. Spatial dynamics of ecosystem service flows: A comprehensive approach to quantifying actual services[J]. Ecosystem Services, 2013, (4): 117-125.

[3] Serna-Chavez H M, Schulp C J E, Van Bodegom P M, et al. A quantitative framework for assessing spatial flows of ecosystem services[J]. Ecological Indicators, 2014, 39: 24-33.

[4] 肖玉, 谢高地, 鲁春霞, 等. 基于供需关系的生态系统服务空间 流动研究进展 [J]. 生态学报, 2016, 36(10): 3096-3102. [Xiao Y, Xie G D, Lu C X, et al. Involvement of ecosystem service flows in 
human wellbeing based on the relationship between supply and demand[J]. Acta Ecologica Sinica, 2016, 36(10): 3096-3102.]

[5] 高吉喜. 区域生态学基本理论探索[J]. 中国环境科学, 2013, 33 (7): 1252-1262. [Gao J X. The basic theoretical exploration of regional ecology[J]. China Environmental Science, 2013, 33(7): 1252-1262.]

[6] Robinson W S. Ecological correlations and the behavior of individuals[J]. American Sociological Review, 1950, 15(3): 351-357.

[7] 高吉喜. 区域生态学[M]. 北京: 科学出版社, 2015. [Gao J X. Region Ecology[M]. Beijing: Science Press, 2015.]

[8] Maass J M, Balvanera P, Castillo A, et al. Ecosystem services of tropical dry forest: Insights from long-term ecological and social research on the Pacific Coast of Mexico[J]. Ecology and Society, 2005, 10(1): 17-17.

[9] Turner W R, Brandon K, Brooks T M, et al. Global biodiversity conservation and the alleviation of poverty[J]. Bioscience, 2012, 62 (1): 85-92.

[10] Palomo I, Martín-López B, Potschin M, et al. National Parks, buffer zones and surrounding lands: Mapping ecosystem service flows [J]. Ecosystem Services, 2013, 4: 104-116.

[11] Xu J, Xiao Y, Xie G D, et al. The spatio-temporal disparities of areas benefitting from the wind erosion prevention service[J]. International Journal of Environmental Research and Public Health, 2018, DOI: 10.3390/ijerph15071510.

[12] 杨丽雯, 董丽青, 张立伟, 等. 固碳服务供需平衡和服务流量化 评估: 以引黄人晋南干线为例 [J]. 资源科学, 2019, 41(3): 557571. [Yang L W, Dong L Q, Zhang L W, et al. Quantitative assessment of carbon sequestration service supply and demand and service flows: A case study of the Yellow River Diversion Project South Line[J]. Resources Science, 2019, 41(3): 557-571.]

[13] 朱文博, 李双成, 朱连奇. 中国省域生态系统服务足迹流动及其 影响因素[J]. 地理研究, 2019, 38(2): 337-347. [Zhu W B, Li S C, Zhu L Q. Ecosystem service footprint flow and the influencing factors within provinces, China[J]. Geographical Research, 2019, 38 (2): 337-347.]

[14] Shi Y S, Shi D H, Zhou L L, et al. Identification of ecosystem services supply and demand areas and simulation of ecosystem service flow in Shanghai[J]. Ecological Indicators, 2020, DOI: 10.1016/j.ecolind.2020.106418.

[15] 严恩萍, 林辉, 党永峰, 等. 2000-2012 年京津风沙源治理区植 被覆盖度时空演变特征[J]. 生态学报, 2014, 34(17): 50075020. [Yan E P, Lin H, Dang Y F, et al. The spatiotemporal changes of vegetation cover in Beijing-Tianjin sandstorm source control region during 2000-2012[J]. Acta Ecologica Sinica, 2014, 34(17): 5007-5020.]

[16] 吴丹, 巩国丽, 邵全琴, 等. 京津风沙源治理工程生态效应评估
[J]. 干早区资源与环境, 2016, 30(11): 117-123. [Wu D, Gong G L, Shao Q Q, et al. Ecological effects assessment of Beijing and Tianjin sandstorm source control project[J]. Journal of Arid Land Resources and Environment, 2016, 30(11): 117-123.]

[17] 李庆旭, 张彪, 王爽, 等. 京津风沙源区 2000-2015年植被覆盖 状况的区域差异研究[J]. 地学前缘, 2018, 25(5): 298-304. [Li Q $\mathrm{X}$, Zhang B, Wang S, et al. Regional differences of vegetation cover in the Beijing-Tianjin sandstorm source region from 2000 to 2015[J]. Earth Science Frontiers, 2018, 25(5): 298-304.]

[18] 巩国丽, 刘纪远, 邵全琴. 草地覆盖度变化对生态系统防风固沙 服务的影响分析: 以内蒙古典型草原区为例[J]. 地球信息科学 学报, 2014, 16(3): 426-434. [Gong G L, Liu J Y, Shao Q Q. Effects of vegetation coverage change on soil conservation service of typical steppe in Inner Mongolia[J]. Journal of Geo-Information Science, 2014, 16(3): 426-434.]

[19] 江凌, 肖炎炎, 饶恩明, 等. 内蒙古土地利用变化对生态系统防风 固沙功能的影响[J]. 生态学报, 2016, 36(12): 3734-3747. [Jiang L, Xiao Y, Rao E M, et al. Effects of land use and cover change ( LUCC) on ecosystem sand fixing service in Inner Mongolia[J]. Acta Ecologica Sinica, 2016, 36(12): 3734-3747.]

[20] 徐志涛, 陈鹏飞, 周世健. 近 10a 京津冀地区生态服务功能变化 [J]. 水土保持通报, 2018, 38(5): 220-226. [Xu Z T, Chen P F, Zhou S J. Change of ecological service in Beijing-Tianjin-Hebei region in recent 10 years[J]. Bulletin of Soil and Water Conservation, 2018, 38(5): 220-226.]

[21] 韩永伟, 王宝良, 刘成程, 等. 关于重点生态功能区生态补偿量 计算中应用辐射效应理论的探讨: 以黑河下游防风固沙重点 功能区为例[J]. 生态经济, 2015, 31(1): 31-34. [Han Y W, Wang B L, Liu C C, et al. Study on ecological compensation of ecological function scheme: Based on the theory of radiation effect[J]. Ecological Economy, 2015, 31(1): 31-34.]

[22] 王凤春, 郑华, 王效科, 等. 生态补偿区域选择方法研究进展 [J]. 生态环境学报, 2017, 26(1): 176-182. [Wang F C, Zheng H, Wang X K, et al. Approaches to spatial targeting identification of payments for ecosystem services[J]. Ecology and Environmental Sciences, 2017, 26(1): 176-182.]

[23] 张予, 刘某承, 白艳芗, 等. 京津冀生态合作的现状、问题与机制 建设[J]. 资源科学, 2015, 37(8): 1529-1535. [Zhang Y, Liu M C, Bai Y Y, et al. Application of ecological conservation cooperation for Beijing-Tianjin-Hebei regional integration[J]. Resources Science, 2015, 37(8): 1529-1535.]

[24] 石莎, 邹学勇, 张春来, 等. 京津风沙源治理工程区植被恢复效 果调查[J]. 中国水土保持科学, 2009, 7(2): 86-92. [Shi S, Zou X Y, Zhang C L, et al. Investigation of vegetation restoration in the area of Beijing and Tianjin sandstorm source control project[J]. Science of Soil and Water Conservation, 2009, 7(2): 86-92.] 
[25] 巩国丽, 刘纪远, 邵全琴. 基于 RWEQ 的 20 世纪 90 年代以来内 蒙古锡林郭勒盟土壤风蚀研究[J]. 地理科学进展, 2014, 33(6): 825-834. [Gong G L, Liu J Y, Shao Q Q. Wind erosion in Xilingol League, Inner Mongolia since the 1990s using the revised wind erosion equation[J]. Progress in Geography, 2014, 33(6): 825834.]

[26] 江凌, 肖淡, 欧阳志云, 等. 基于 RWEQ 模型的青海省土壤风蚀 模数估算[J]. 水土保持研究, 2015, 22(1): 21-25. [Jiang L, Xiao Y, Ouyang Z Y, et al. Estimate of the wind erosion modules in Qinghai Province based on RWEQ model[J]. Research of Soil and Water Conservation, 2015, 22(1): 21-25.]

[27] 申陆, 田美荣, 高吉喜, 等. 浑善达克沙漠化防治生态功能区防 风固沙功能的时空变化及驱动力[J]. 应用生态学报, 2016, 27 (1): 73-82. [Shen L, Tian M R, Gao J X, et al. Spatio-temporal change of sand-fixing function and its driving forces in desertification control ecological function area of Hunshandake, China[J]. Chinese Journal of Applied Ecology, 2016, 27(1): 73-82.]

[28] 高尚玉, 邹学勇, 张春来, 等. 京津风沙源治理工程效益[M]. 北 京: 科学出版社, 2008. [Gao S Y, Zou X Y, Zhang C L, et al. Benefits of Beijing-Tianjin Sand Source Control Engineering[M]. Beijing: Science Press, 2008.]

[29] 覃云斌, 信忠保, 易扬, 等. 京津风沙源治理工程区沙尘暴时空 变化及其与植被恢复关系 [J]. 农业工程学报, 2012, 28(24): 196-204. [Qin Y B, Xin Z B, Yi Y, et al. Spatiotemporal variation of sandstorm and its response to vegetation restoration in BeijingTianjin sandstorm source area[J]. Transactions of the Chinese Society of Agricultural Engineering, 2012, 28(24): 196-204.]

[30] 王晓欢, 王晓峰, 秦慧杰. 西安市生态文明建设评价及预测[J]. 城市环境与城市生态, 2010, 23(2): 5-8. [Wang X H, Wang X F, Qin H J. Evaluation and predication of ecological civilization construction in Xi' an[J]. Urban Environment \& Urban Ecology, 2010, 23(2): 5-8.]

[31] 吴小节, 彭韵妍, 汪秀琼. 中国生态文明发展状况的时空演变与 驱动因素 [J]. 干旱区资源与环境, 2016, 30(8): 1-9. [Wu X J, Peng Y Y, Wang X Q. The spatial-temporal evolution and driving factors of ecological civilization of 31 provincial administrative regions[J]. Journal of Arid Land Resources and Environment, 2016, 30(8): 1-9.]

[32] 许月卿, 贾秀丽. 近 20 年来中国区域经济发展差异的测定与评 价[J]. 经济地理, 2005, 25(5): 600-603. [Xu Y Q, Jia X L. The measurement and evaluation of regional economic development disparities in China recent 20 years[J]. Economic Geography, 2005, 25(5): 600-603.]

[33] 李庆旭, 张彪, 史芸婷, 等. 张承地区生态系统服务及其区域关
联分析[J]. 生态与农村环境学报, 2017, 33(1): 38-46. [Li Q X, Zhang B, Shi Y T, et al. Key ecosystem services and their regional flow in Zhangjiakou-Chengde region[J]. Journal of Ecology and Rural Environment, 2017, 33(1): 38-46.]

[34] 郜红娟, 蔡广鹏, 韩会庆, 等. 贵州省贫困发生率与生态系统服 务价值相关性分析[J]. 水土保持研究, 2016, 23(5): 274-277. [Gao H J, Cai G P, Han H Q, et al. Correlation analysis between poverty incidence and ecosystem service value in Guizhou Province[J]. Research of Soil and Water Conservation, 2016, 23(5): 274-277.]

[35] 陈婧神, 罗红霞, 胡林利, 等. 生态系统服务价值与社会经济相 关性研究: 以重庆市大都市区为例[J]. 水土保持研究, 2017, 24 (4): 330-336. [Chen J Y, Luo H X, Hu L L, et al. Correlation between social economic development and ecosystem service value A case of Chongqing Metropolitan Area[J]. Research of Soil and Water Conservation, 2017, 24(4): 330-336.]

[36] 董治宝, 高尚玉, 董光荣. 土壤风蚀预报研究述评[J]. 中国沙漠, 1999, 19(4): 312-317. [Dong Z B, Gao S Y, Dong G R. A review of wind erosion prediction research[J]. Journal of Desert Research, 1999, 19(4): 312-317.]

[37] 邹学勇, 张春来, 程宏, 等. 土壤风蚀模型中的影响因子分类与 表达[J]. 地球科学进展, 2014, 29(8): 875-889. [Zou X Y, Zhang $\mathrm{C} \mathrm{L}$, Cheng $\mathrm{H}$, et al. Classification and representation of factors affecting soil wind erosion in a model[J]. Advances in Earth Science, 2014, 29(8): 875-889.]

[38] 沈建国, 孙照渤, 章秋英, 等. 干早草原地区起沙通量的初步研 究 [J]. 中国沙漠, 2008, (6): 1045-1049. [Shen J G, Sun Z B, Zhang Q Y, et al. Preliminary study on dust emission rate over arid steppe area[J]. Journal of Desert Research, 2008, (6): 1045-1049.]

[39] 李晓岗, 张宏升. 内蒙古科尔沁沙地起沙近地层动力学國值的 试验研究[J]. 高原气象, 2012, 31(1): 38-46. [Li X L, Zhang H S. Study on the threshold friction velocity of dust emission in Horqin Sand Land Area in the Inner Mongolia[J]. Plateau Meteorology, 2012, 31(1): 38-46.]

[40] 张登山, 张佩, 吴汪洋, 等. 青海湖东克土沙区风沙运动规律及 防治对策 [J]. 中国沙漠, 2016, 36(2): 274-280. [Zhang D S, Zhang $\mathrm{P}, \mathrm{Wu} \mathrm{W}$ Y, et al. Wind-blown sand activity and control way of sand hazards at Ketu Sandy Land in Eastern Shore of the Qinghai Lake[J]. Journal of Desert Research, 2016, 36(2): 274280.]

[41] Li Q X, Zhang B, Xie G D, et al. Identification of key ecosystem services that can be delivered by water or wind from ZhangjiakouChengde region to Beijing[J]. Journal of Resources and Ecology, 2018, 9(6): 632-641. 


\title{
Regional correlation degree derived from the sand-fixing service spatial flow:
}

\section{A case study of the Beijing-Tianjin sandstorm control engineering area}

\author{
ZHANG Biao ${ }^{1,2}$, WANG Shuang ${ }^{1,2}$, LI Qingxu', ${ }^{1,2}$ XIE Gaodi1,2 \\ (1. Institute of Geographic Sciences and Natural Resources Research, CAS, Beijing 100101, China; \\ 2. University of Chinese Academy of Sciences, Beijing 100049, China)
}

\begin{abstract}
Ecosystem service spatial flow is the delivery of an ecosystem service to people or the movement of material and people. Its assessment elucidates the dominant contributors of ecosystem services and their spatial relationships. In this study, we defined a concept of regional correlation degree as the flow quantity of ecosystem services from a supply area to a demand area, which can be used as an important reference for regional ecological compensation. Based on the characteristics of wind direction and spatial location in the Beijing- Tianjin sandstorm control engineering area, this study developed a regional correlation model with the provision degree and influencing degree of sand-fixing services. Subsequently, we estimated the sand-fixing services in the sandstorm control engineering area in 2015 by the revised wind erosion equation (RWEQ), and analyzed the ecological links between different administrative districts of the sandstorm control engineering area and Beijing Municipality. The results indicate that the regional correlation degrees of sand-fixing services ranged from 0 to $13.43 \%$. Chicheng County in Zhangjiakou City presented the highest correlation degree with Beijing, and the high correlation zones of sand-fixing services were Sunnitezuo Banner, Xuanhua District, Huaian County, Xiahuayuan District, and Suniteyou Banner. However, Wengniute Banner, Chengde County, Ningcheng County, Jixian County, and Yangyuan County showed the lowest ecological links with Beijing in sand-fixing services. The regional correlation of sand-fixing services was generally high in the west and low in the east. This phenomenon mainly can be attributed to the predominant wind direction in the Beijing-Tianjin sandstorm control engineering area, and the spatial heterogeneities of sand- fixing services. Additionally, the social and economic development levels in different districts presented negative correlation with the correlation degree of sand-fixing services. This result implies that the regions of higher correlation degree of sand-fixing services with Beijing were suffering from more severe poverty. Therefore, we concluded that Beijing should pay more ecological compensation to those counties with high correlation degrees in sand-fixing services to ensure the sustainable provision of sand-fixing services.
\end{abstract}

Key words: sand-fixing services; spatial flow; ecological relationship; regional correlation degree; Beijing-Tianjin sandstorm control engineering area 